\title{
Evaluation Relationship Among Dental Fear, SRP Pain and Periodontal Status Using Periodontitis Stages: A Retrospective Study
}

\section{Yeungyeung Liu}

Stomatological Hospital, Southern Medical University

\section{Caimei Zhang}

Stomatological Hospital, Southern Medical Univeristy

Jingyi Wu

Stomatological Hospital, Southern Medical University

Huimin $\mathrm{Yu}$

Stomatological Hospital, Southern Medical University

\section{Duoling Xu}

Stomatological Hospital, Southern Medical University

Chengjie Xie ( $\nabla$ chengjie.xie@hotmail.com )

Stomatological Hospital,Southern Medical University

\section{Research article}

Keywords: dental fear, periodontal status, SRP pain, periodontitis stage

Posted Date: June 1st, 2020

DOI: https://doi.org/10.21203/rs.3.rs-31624/v1

License: (c) (i) This work is licensed under a Creative Commons Attribution 4.0 International License. Read Full License 


\section{Abstract}

Background: The present study used the new classification of periodontitis and validated questionnaires to assess the relationship among dental fear, SRP pain and periodontal status for clinical evaluation.

Methods: An amount of 120 periodontitis patients were retrospective analyzed and staged according to the new classification of periodontitis. Scaling and root planning (SRP) was performed and Visual analogue scales (VAS) applied immediately after SRP treatment. Application of questionnaires including Corah's Dental Anxiety Scales (DAS), Dental Fear Survey (DFS), and the short-form Dental Anxiety Inventory (S-DAl) were adopted at the time of first attendance and consequent visit after 6 months to assess dental fear level. The scores of each dental fear scale and combination scales were recorded. Patients were divided into two categories according to DAS value (low dental fear group: DAS<13; high dental fear group: DAS $\geq 13$ ). The statistical analysis was performed by t-test, chi-square, pearson and spearman correlative analysis to evaluated the relationship and differences among dental fear, SRP pain and periodontal status.

Results: Compared to pre-SRP treatment, dental fear level of DFS and combination scales were significantly decreased in post-treatment in all periodontitis stage. There were no statistical significance on dental fear level of S-DAI and DFS between patients pre and post-treatment in periodontitis stage I and II, while statistical significance were shown in stage III and IV. Correlation were statistical significance among dental fear level assessed by DAS, DFS and S-DAI, VAS and periodontitis stages. Significant differences of patient amount were shown between two categories according to DAS.

Conclusions: SRP can reduce dental fear level in all periodontitis stages, especially stage III and IV. Correlations exist among periodontal status, dental fear and SRP pain. High dental fear relates to poor periodontal status.

\section{Background}

Periodontal disease is one of the two most important oral diseases, which is highly prevalent worldwide and represents a major public health problem in many countries. A recent systematic analysis for the Global Burden of Disease Study 2016 indicated that severe periodontal disease, which may cause tooth loss, was the 11th most prevalent disease worldwide [1, 2]. Non-surgical periodontal therapy, known as scaling and root planning (SRP), is the most common procedure and remains the gold standard of successful periodontal therapy [3]. It was found to be an effective treatment in reducing probing depth and improving the clinical attachment level $[4,5]$. However, the experience of pain and sensitive during treatment, may discourage the patients attendances and increase the level of dental fear [6].

Dental fear is a substantial public health problem, which affects $5-20 \%$ adults of the world, ranging from a mild sensation of apprehension to prominent fear and dental phobia [7-9]. In previous study, dental fear was related to less frequent dental visiting, poorer oral health and greater functional impairment [10]. Dental fear negatively affects the treatment outcomes and leads to avoidance of dental treatment [6]. 
There is a vicious cycle of dental fear, whereby the experience of dental fear results in greater avoidance of and delay in dental visiting, deteriorated oral health with higher treatment needs and the tendency to visit the dentist for the purpose of relieving a problem, rather than for a check-up [11].

It was reported that patients with periodontal disease had higher dental fear level [12]. Fear of treatment could affect patient compliance and result in periodontal deterioration. Continuous high level of dental fear caused by experiencing discomfort or pain in periodontal treatment process might have negative effects on clinical outcome.

Periodontal status was related to dental fear level and pain experience during treatment. Previous study reported that patient with higher fear showed a worse clinical periodontal status [13]. Pain per se and memory of pain were proved to the stimuli elements to induce dental fear [14]. In addition, sites of bleeding on probing(BOP) and sites $\geq 4 \mathrm{~mm}$ probing depth also caused higher VAS scores[15]. Some studies assess the periodontal severity by probing depth, clinical attachment loss or BOP to evaluate the relationship between the dental fear level and pain feelings $[16,17]$. Therefore, dental fear, SRP pain and periodontal status were correlative with each other.

Previous studies reported the relationship among dental fear, SRP pain and periodontal status in different aspects $[1,8,13]$. From 2018 , the new classification of periodontitis was widely used in clinical, but relative research on dental fear was insufficient $[18,19]$.

The present study used the new classification of periodontitis and validated questionnaires to assess the relationship among dental fear, SRP pain and periodontal status for clinical evaluation.

\section{Methods}

\section{Study design}

The patients, who presented from July 2018 to January 2020 at the Outpatient Clinics of Stomatological Hospital, Southern Medical University, to perform the questionnaires. Written informed consent for participation was obtained from all participants prior to the investigation. The present study was approved by the Ethical Committee, Stomatological Hospital of Southern Medical University.

The following inclusion criteria were adopted: 1. diagnosis as periodontitis (American Academy of Periodontology,AAPख2018)[20]; 2. aged 35-65 years old; 3. at least 4 natural teeth per quadrant (one incisor, one canine, one premolar and one molar) with healthy pulp status; 4 . no dentin hypersensitivity. Exclusion criteria were: 1. periodontal treatment including scaling and root planing procedures within 12 months. 2. utilization of antibiotics or anti-inflammatory drugs within 1 month; 3 . use desensitizing toothpaste within 1 month; 4. pregnancy and lactation; 5 . history indicative of a medical or psychological disorder that may affect normal pain perception, or taking any stress or pain medication; 6 . smoking or alcohol abuse; 7. systemic disease.

\section{Study population}


An amount of 120 periodontitis patients were retrospective analyzed and staged according to the new classification of periodontal disease (2018), which assessed by the level of interdental clinical attachment loss, probing depth,radiographic bone loss and tooth loss. There were 4 stages available, including stage I, II, III and IV [20]. Periodontal examination including probing depth(PD)【clinical attachment level (CAL) and were assessed at the first attendance. Measurements of PD and CAL were obtained at six sites per tooth in all present teeth. After periodontal examination, sailing and root planing (SRP) was performed with Gracey curettes until the root surfaces were hard and smooth. The VAS scale applied immediately after SRP treatment. Application of DAS, DFS and S-DAl questionnaires were adopted at the time of first attendance and consequent visit after 6 months. Every procedure was operated by one doctor and without previous analgesics.

\section{Questionnaires DAS, DFS and S-DAI}

Prior to the procedure, the patient was interviewed to collect the questionnaires to assess the dental fear. The questionnaire included 3 separated tests: Corah's Dental Anxiety Scales (DAS), Dental Fear Survey (DFS), and the short-form Dental Anxiety Inventory (S-DAI), and was composed of 33 multiple-choice questions in total. The DAS presents four questions related to concerns about visiting the dentist [21], with the first two questions relating to general anxiety and the second two questions relating to anticipated fear of specific stimuli. A score of 13 or greater on the DAS was defined as "high dental fear", as widely accepted previously [22]. The DAS was the most widely used dental fear scale for adults, which reported good reliability and validity. However, it failed to provide additional information regarding what the patient specifically fears. Therefore, the Dental Fear Survey (DFS) was also applied for compensation, which consisted of 20 items with five alternative answers to each, rating from high to low intensity [23, 24]. The S-DAl with 9 items, which was established by Stouthard et al [25], was also used to assess physical reactions, thoughts and behavioral aspects of dental fear experienced by the individual [26]. The DFS and S-DAl both had good reliability and validity tested Chinese version $[27,28]$.

General information besides questionnaire contained social-demographic features including gender, age, education and marital status.

\section{Visual Analogue Scale}

Pain level were evaluated by Visual analogue scales (VAS). This scale is the most frequently used method to assess pain intensity. It is a horizontal line labelled at each end from 0 to $10 \mathrm{~cm}$, where individuals mark their level of pain[29, 30].It was applied in a standard manner with an initial explanation clarifying that 0 mean no pain and discomfort, while 10 mean a very intense pain and very discomfort[13].VAS score was performed immediately after the scaling and root planing (SRP) treatment.

\section{Data analysis}

T-test was used to analyze the differences of dental fear pre-and post-SRP treatment. Pearson and Spearman correlative analysis were used to analyze correlations among dental fear values, VAS and periodontitis stages. Chi-square was performed to evaluated the periodontitis severity in different dental 
fear patients. For all statistical analysis, $P$ values were two-tailed and level of significance was set at $P=$ 0.05 .

\section{Results}

The current study retrospective analyzed 120 periodontitis patients of average age $43.3 \pm 5.98$ including 64 male (53.33\%) and 56 female (46.67\%). According to the periodontal status, all patients were divided into 4 stage groups. No significant differences were shown among groups on age, gender, educational level and marriage status. $(P>0.05)$ Periodontal indicators and background characteristics were shown in Table 1.

Table 1

Periodontal indicators and demographics of four periodontitis stages

\begin{tabular}{|llllll|}
\hline Periodontitis & Stage I & Stage II & Stage III & Stage IV & $\boldsymbol{P}$ \\
Stage & $\mathbf{n = 3 0}$ & $\mathbf{n = 3 0}$ & $\mathbf{n = 3 0}$ & $\mathbf{n = 3 0}$ & \\
\hline Age & $41.70 \pm 5.96$ & $43.17 \pm 4.78$ & $43.33 \pm 6.09$ & $45.13 \pm 6.72$ & 0.173 \\
\hline Gender (M:F) & $14: 16$ & $15: 15$ & $17: 13$ & $16: 14$ & 0.885 \\
\hline Marriage & $83.33 \%$ & $86.67 \%$ & $83.33 \%$ & $80.00 \%$ & 0.983 \\
\hline Education & $2.73 \pm 0.45$ & $2.67 \pm 0.48$ & $2.57 \pm 0.50$ & $2.53 \pm 0.63$ & 0.426 \\
\hline PD & $2.28 \pm 0.18$ & $2.46 \pm 0.24$ & $3.72 \pm 0.23$ & $3.86 \pm 0.32$ & - \\
\hline CAL & $1.67 \pm 0.19$ & $2.72 \pm 0.25$ & $3.82 \pm 0.27$ & $4.13 \pm 0.36$ & - \\
\hline PD, Probing Depth; CAL, Clinical Attachment Level. & & \\
\hline
\end{tabular}

00From the dental fear questionnaires, compared to pre-SRP treatment, dental fear level of DFS and combination scales were significantly decreased in post-treatment in all periodontitis stage. There were no statistical significance on dental fear level of S-DAI and DFS between patients pre- and post-treatment in periodontitis stage I and II, while statistical significance were shown in stage III and IV. (Table 2) 
Table 2

Comparative analysis of dental fear between pre- and post-SRP in four periodontitis stages

\begin{tabular}{|c|c|c|c|c|c|c|c|c|}
\hline & \multicolumn{2}{|l|}{ DAS } & \multicolumn{2}{|l|}{ DFS } & \multicolumn{2}{|l|}{ S-DAl } & \multicolumn{2}{|c|}{ Combination } \\
\hline & pre-SRP & $\begin{array}{l}\text { post- } \\
\text { SRP }\end{array}$ & pre-SRP & post-SRP & $\begin{array}{l}\text { pre- } \\
\text { SRP }\end{array}$ & $\begin{array}{l}\text { post- } \\
\text { SRP }\end{array}$ & pre-SRP & post-SRP \\
\hline I & $\begin{array}{l}9.17 \pm \\
1.98\end{array}$ & $\begin{array}{l}8.20 \pm \\
2.06\end{array}$ & $\begin{array}{l}38.03 \pm \\
5.89\end{array}$ & $\begin{array}{l}34.70 \pm \\
6.20^{*}\end{array}$ & $\begin{array}{l}21.40 \\
\pm 6.79\end{array}$ & $\begin{array}{l}18.63 \pm \\
5.90\end{array}$ & $\begin{array}{l}68.60 \pm \\
10.29\end{array}$ & $\begin{array}{l}61.53 \pm \\
9.56^{\star}\end{array}$ \\
\hline II & $\begin{array}{l}10.77 \pm \\
3.00\end{array}$ & $\begin{array}{l}9.07 \pm \\
3.67\end{array}$ & $\begin{array}{l}45.03 \pm \\
14.88\end{array}$ & $\begin{array}{l}37.63 \pm \\
11.89 *\end{array}$ & $\begin{array}{l}26.53 \\
\pm 9.17\end{array}$ & $\begin{array}{l}23.43 \pm \\
9.02\end{array}$ & $\begin{array}{l}82.33 \pm \\
19.75\end{array}$ & $\begin{array}{l}70.13 \pm \\
17.04^{\star}\end{array}$ \\
\hline III & $\begin{array}{l}11.10 \pm \\
4.16\end{array}$ & $\begin{array}{l}8.97 \pm \\
3.97 *\end{array}$ & $\begin{array}{l}48.93 \pm \\
16.47\end{array}$ & $\begin{array}{l}40.13 \pm \\
13.87^{\star}\end{array}$ & $\begin{array}{l}27.97 \\
\pm 9.69\end{array}$ & $\begin{array}{l}22.83 \pm \\
9.14^{\star}\end{array}$ & $\begin{array}{l}88.00 \pm \\
19.50\end{array}$ & $\begin{array}{l}71.93 \pm \\
15.92^{\star}\end{array}$ \\
\hline IV & $\begin{array}{l}12.03 \pm \\
4.06\end{array}$ & $\begin{array}{l}9.57 \pm \\
3.89^{*}\end{array}$ & $\begin{array}{l}54.87 \pm \\
18.44\end{array}$ & $\begin{array}{l}42.30 \pm \\
15.94^{\star}\end{array}$ & $\begin{array}{l}30.63 \\
\pm 7.92\end{array}$ & $\begin{array}{l}24.47 \pm \\
8.23^{*}\end{array}$ & $\begin{array}{l}97.53 \pm \\
21.65\end{array}$ & $\begin{array}{l}76.33 \pm \\
20.28^{\star}\end{array}$ \\
\hline \multicolumn{9}{|c|}{ *:Compared to Pre-SRP, Significantly different, $P<0.05$} \\
\hline \multicolumn{9}{|c|}{ Combination $=$ DAS + DFS + S-DAI } \\
\hline
\end{tabular}

The results of correlative analysis revealed the relationship among dental fear, VAS and periodontitis stage in Table 3. Correlation were statistical significance on dental fear level assessing DAS, DFS and SDAI, VAS and periodontitis stage.

Table 3

Correlation among periodontitis stage, dental fear and VAS

\begin{tabular}{|c|c|c|}
\hline & VAS & periodontitis stage \\
\hline DAS & $0.531^{\star \star}$ & $0.281^{*}$ \\
\hline DFS & $0.476^{\star \star}$ & 0.380 ** \\
\hline S-DAl & $0.200 *$ & $0.375^{\star \star}$ \\
\hline Combination & $0.533^{* *}$ & $0.493 * \star$ \\
\hline \multicolumn{3}{|c|}{$\star: P<0.05, * *: P<0.01$} \\
\hline \multicolumn{3}{|c|}{ Combination $=$ DAS + DFS + S-DAI } \\
\hline
\end{tabular}

High dental fear was defined by the score of 13 or greater access the DAS scale, as widely accepted previously [22]. We separated the patients into two categories, which were low dental fear group(DAS < $13)$ and high dental fear group(DAS $\geq 13)$. The number of patients of Group A was $2(6.45 \%)$ in stage I, $5(16.13 \%)$ in stage II, $11(35.48 \%)$ in stage III and $13(41.94 \%)$ in stage IV. While the number of Group B was $28(31.46 \%)$ in stage I, 25(28.09\%) in stage II, 19 (21.35\%)in stage III and $17(19.10 \%)$ in stage IV. Significant differences were shown between two categories. (Fig. 1) 


\section{Discussion}

\section{New periodontitis classification to evaluate periodontal status}

This study evaluated periodontal status by the new periodontitis classification in 2018. Previous classification in 1999 was used extensively but suffered from substantial overlap and lack of clear pathobiology-based distinction [20]. The new classification assessed periodontitis by stages and grades. Staging depended upon the severity of disease presented the complexity of disease management, while grading provided supplemental information about biological features of the disease [20]. The staging was assessed by level of interdental clinical attachment loss, radiographic bone loss and tooth loss (Stage I-II-III-IV) [18]. Population of this study had no systematic diseases and history of smoking, and the time of consequent visits were 6 months. In this case, we did not put grading into population assessment in this study.

\section{The combination of three dental fear scales}

Dental fear should be studied with regard to the situation to which it pertains, the reactions it evokes, and its duration [12]. Every single scale of dental fear can describe one aspect very well but relatively incomprehensive. This study used three scales, including DAS, DFS and S-DAI, to evaluate dental fear in different aspects. DFS reflects dental fear informatively to help clinicians understand a patient's fear better, while DAS measures dental fear generally [31]. S-DAl focuses on psychometric grounds [25], of which nearly half of its items reflect the emotional reactions [12, 31].

The levels of dental fear were significantly decreased at patients subsequent visit after 6 months in most scales except stage I and II of DAS and S-DAl, because of the different concentration of the three scales, particularly in S-DAl, which was focused on psychometric grounds. The response categories of DAS were not comprehensive to evaluate the anticipated fear of specific stimuli [31]. Santuchi et al, reported significantly lower dental fear level at the first attendances on DAS, but no statistical significance on DFS [13]. Researchers drew different conclusions for the same concerned problem from different scales. Although the statistical significance of each scale was diverse, the combination of three dental fear scales was consistently decreased at the time of 6 months subsequent visiting, while the trend from mean number of all scales also showed decrease. In this case, combination with three scales in the present study could enhance the accuracy of the results.

\section{Periodontal status, dental fear and pain}

Periodontal status was an important factor affecting dental fear, and poor periodontal status could contribute to high dental fear [12]. The present study exhibited correlations between periodontitis stages and dental fear, reflecting worse periodontitis with higher dental fear. Many emerging evidences had indicated that periodontal status was associated with dental fear. Guentsch et al suggested that patients with higher dental fear value showed more sites of bleeding on probing (BoP), which had negative effects 
on periodontal health [32]. Levin et al illustrated periodontal clinical parameters, including plaque index, radiographic bone loss and probing depth were correlated with DAS [8]. Bell et al reported that dental fear was associated with bleeding gums as signs of gingivitis [33]. These literatures were in agreement with the findings of the present study. However, there were also reports describing no association of dental fear and poor periodontal health. Delgado-Angulo et al concluded that dental fear was not related to the number of teeth with $P D \geqq 4 m m[17]$, while Eitner et al identified that anxious was not associated with periodontal status[34]. Besides, these findings suggested that important to evaluate dental fear levels for successful treatment of a periodontitis patient.

Pain is an 'unpleasant sensory and emotional experience associated with actual or potential tissue damage, or described by the patient in terms of such damage' [35]. As a major component of dental fear, fear of pain associated with dental treatment has been identified [36]. SRP is often associated with pain and discomfort, although pain occurrence is variable and dramatically different among patients [16]. The VAS of the pain perceived during periodontal procedures range from approximately $20-80 \mathrm{~mm}[37,38]$. VAS during SRP in this study was $24.79 \pm 14.61$, which was significant associated with dental fear. Our findings were corroborated by Tickle et al, who found that subjects with dental fear were 2.3 times more likely to experience pain after dental treatment than patients without dental fear [39]. Fardal \& McCulloch also demonstrated that patients with high dental fear scores reported greater pain after periodontal therapy [40]. The negative reinforcement of aversive stimuli avoidance including pain, anticipation or memory of pain, and environmental factors, also identified the association between dental fear and postoperative pain [41]. It suggested periodontal treatment should lead professionals to design health and comfort treatment strategies that will cope with the dental fear and reduced discomfort during treatment [16].

In the present study, dental fear, pain and periodontal status were significantly correlated with each other. Individuals, who had high dental fear, would delay treatment, and lead to more extensive development of disease, which ultimately required more invasive and potentially painful treatment, and these experience could contribute to the increase of dental fear: this is the idea of a 'vicious cycle'[42]. The level of dental fear in periodontitis patients was higher, and the poor periodontal status was related to dental fear in the present study. In this case, without intervention of SRP, the periodontal status would be exacerbated because of high level of dental fear, then resulting in periodontitis aggravation, and the vicious cycle established. Hence, periodontitis patients should be noticed by clinicians to the level of dental fear and break this cycle. The dental fear value were all reduced in every stage of periodontitis patients, especially in stage III and IV were significantly reduced, which suggested intervention treatment necessary. Santuchi et al reported that periodontal clinical were improved and experiences of fear were reduced during SRP, which was similar to our study [13].

The proportion of periodontitis stage III(35.48\%) and IV(41.94\%)in high dental fear group was significantly increased compare to low dental fear group(stage III $21.34 \%$, stage IV 19.10\%). After 6 months return visit, although the dental fear level of patients were reduced compared to the first attendance, the dental fear value were still high, especially in stage III and IV periodontitis patients. 
According to the new periodontitis classification in 2018, stage I and II were considered to initial and moderate periodontitis, while stage III and IV were severe and advanced periodontitis [43]. This was in line with other studies demonstrating that patients with severe periodontitis had poorer oral health, worse functional limitation, physical pain, and psychological incapacity domain scores, than those with mild and moderate periodontitis [44]. To the best of our knowledge, this is the first study in the literature that measured periodontal status by periodontitis stages to evaluate relationship between dental fear and pain. Based on the above study, it should pay more attention to notice periodontitis patients dental fear level, especially stage III and IV periodontitis by clinicians.

The sample of current study was relatively small although statistically enough. Secondly, long term follow-up could advance questionnaire accuracy. Grading assessment in the further study can supply clinical evaluation of new periodontitis classification.

\section{Conclusions}

SRP can reduce dental fear level in all periodontitis stage, especially stage III and IV. Correlation exist among periodontal status, dental fear and SRP pain. High dental fear relates to poor periodontal status.

\section{Abbreviations}

SRP

scaling and root planing; VAS:Visual Analogue Scale; DAS:Corach's Dental Anxiety Scales; DFS:Dental Fear Survey; S-DAl:short-form Dental Anxiety Inventory; BOP:bleeding on probing; PD:probing depth;CAL:clinical attachment level

\section{Declarations}

\section{Ethics approval and consent to participate}

The present study was approved by the Ethical Committee, Stomatological Hospital of Southern Medical University. Written informed consent for participation was obtained from all participants prior to the investigation

\section{Consent for publication}

Not applicable

\section{Availability of data and materials}

The datasets used and analyzed during the current study are available from the corresponding author on reasonable request.

\section{Competing interests}


The authors declare that they have no competing interests.

\section{Funding}

This study was financially supported by Medical and Science Foundation of Guangdong Province(A2017244). The funds were used for interpretation of data and manuscript editing.

\section{Authors' contributions}

LYY carried out the study implementing and drafted the manuscript. ZCM and WJY contributed with statistical analysis. YHM and XDL participated in data analysis and interpretation of data revised critically. XCJ conceived of the study, and participated in its design and coordination and helped to draft the manuscript. All authors read and approved the final version of the manuscript.

\section{Acknowledgments}

Not applicable

\section{References}

1. Paksoy T, Ustaoğlu G, Peker K. Association of socio-demographic, behavioral, and comorbidityrelated factors with severity of periodontitis in Turkish patients. Aging male. 2020;4(11):1-10.

2. Vos T, Abajobir AA, Abate KH. Global. Regional, and national incidence, prevalence, and years lived with disability for 328 diseases and injuries for 195 countries, 1990-2016: a systematic analysis for the Global Burden of Disease Study 2016. Lancet. 2017;390(10100):1211-59.

3. Chen MH, Yin HJ, Chang HH, Kao CT, Tu CC, Chen YW. Baseline probing depth and interproximal sites predict treatment outcomes of non-surgical periodontal therapy. J Dent Sci. 2020;15(1):50-8.

4. Van der Weijden GA, Timmerman MF. A systematic review on the clinical efficacy of subgingival debridement in the treatment of chronic periodontitis. J Clin Periodontol. 2002;29(Suppl 3):55-71.

5. Cobb CM. Clinical significance of non-surgical periodontal therapy: an evidence-based perspective of scaling and root planing. J Clin Periodontol. 2002;29(Suppl 2):6-16.

6. Guzeldemir E, Toygar HU, Cilasun U. Pain perception and anxiety during scaling in periodontally healthy subjects. J Periodontol. 2008;12(79):2247-55.

7. Meng X. Effect of fear on dental utilization behaviors and oral health outcome. Community Dent Oral Epidemiol. 2007;35(4):292-301.

8. Weiss M, Zini, Avraham L, Ron A, et al. Dental anxiety and oral health-related quality of life in aggressive periodontitis patients. Clin Oral Invest. 2018;3(22):1411-22.

9. Almozninoa G, Zinib A, Aframianc DJ, Kaufmanc E, Lvovskyd A, Hadad A, Levin L. Demographic profile, plaque index and DMFT scores of young individuals with dental anxiety and exaggerated gag reflex. Oral Health Prev Dent. 2015;2(13):123-8. 
10. Armfield JM. Predicting dental avoidance among dentally fearful Australian adults. Eur J Oral Sci. 2013;121(3 Pt 2):240-6.

11. Armfield JM. What goes around comes around: revisiting the hypothesized vicious cycle of dental fear and avoidance. Community Dent Oral Epidemiol. 2013;41(3):279-87.

12. Liu $Y$, Huang $X$, Yan $Y$, Lin $H$, Zhang J, Xuan D. Dental fear and its possible relationship with periodontal status in Chinese adults: a preliminary study. BMC oral health. 2015;15:18.

13. Santuchi CC, Cortelli SC, Cortelli JR, Cota LOM, Alencar CO, Costa FO. Pre- and post-treatment experiences of fear, anxiety, and pain among chronic periodontitis patients treated by scaling and root planing per quadrant versus one-stage full-mouth disinfection: a 6-month randomized controlled clinical trial. J Clin Periodontol. 2015;42(11):1024-31.

14. McNeil DW, Randall CL. Dental fear and anxiety associated with oral health care: conceptual and clinical issues. Behavioral Dentistry; 2014.p. 165-192.

15. Canakci V, Canakci CF. Pain levels in patients during periodontal probing and mechanical nonsurgical therapy. Clin Oral Invest. 2007; (11): 377-83.

16. Schirme C, Otero dos Santo G, Ros JF, Ferreira MBC, Weidlic P. Fators associated with pain and analgesic consumption following non-surgical periodontal therapy under local anesthesia and carried out by dental students. J Clin Periodontol. 2017;1(45):68-77.

17. Delgado-Angulo EK, Sabbah W, Suominen AL, Vehkalahti MM, Knuuttila M, Partonen T, et al. The association of depression and anxiety with dental caries and periodontal disease among Finnish adults. Community Dent Oral Epidemiol. 2015;43(6):540-9.

18. Alcione O, Fernando C, Letícia N, Sheila C, Peterson O, Davi A, et al. Azithromycin and Full-Mouth Scaling For the Treatment of Generalized Stage III and IV Periodontitis A 6-Month Randomized Comparative Clinical Tria. Braz Dent J. 2019;5(30):429-36.

19. Karaaslan F, Dikilitas A. The association between stage-grade of periodontitis and sleep quality and oral health-related quality of life. J Periodontol. 2019;90(10):1133-41.

20. Papapanou PN, Sanz M, Buduneli N, Dietrich T, Feres M, Fine DH, et al. Periodontitis: Consensus report of workgroup 2 of the 2017 World Workshop on the Classification of Periodontal and PeriImplant Diseases and Conditions. J Periodontol. 2018;89(Suppl 1):173-82.

21. Corah NL. Development of a Dental Anxiety Scale. J Dent Res. 1969;4(48):596.

22. Armfield JM. The extent and nature of dental fear and phobia in Australia. Aust Dent J. 2010;55(4):368-77.

23. Kleinknecht RA, Klepac RK, Alexander LD. Origins and characteristics of fear of dentistry. J Am Dent Assoc. 1973;86(4):842-8.

24. Kleinknecht RA, Bernstein DA. The assessment of dental fear. Behav Ther. 1978;9(4):626-34.

25. Stouthard MEA, Mellenbergh GJ, Hoogstraten J. Assessment of dental anxiety: a facet approach. Anxiety Stress Coping. 1993;6(2):89-105. 
26. Porritt J, Buchanan H, Hall M, Gilchrist F, Marshman Z. Assessing children's dental anxiety: a systematic review of current measures. Community Dent Oral Epidemiol. 2013;41(2):130-42.

27. Liang HY, Peng ZI, Pan JY, Tang Q, Wang P. Development and Evaluation of Chinese Version of Dental Fear Survey (DFS). J Sun Yat-sen Univ (Medical Sciences). 2006;27(2):236-40.

28. Ng SK, Stouthard ME, Keung Leung W. Validation of a Chinese version of the dental anxiety inventory. Community Dent Oral Epidemiol. 2005;33(2):107-14.

29. Joyce CRB, Zutshi DW, Hrubes VF, Mason RM. Comparison of fixed interval and visual analogue scales for rating chronic pain. Eur J Pharmacol. 1975;8(6):415-20.

30. Huskisson EC. Measurement of pain. J Rheumatol. 1982;(9):768-9.

31. Armfield JM. How do we measure dental fear and what are we measuring anyway? Oral Health Prev Dent. 2010;8(2):107-15.

32. Guentsch A, Stier C, Raschke GF, Peisker A, Fahmy MD, Kuepper H, et al. Oral health and dental anxiety in a German practice-based sample. Clin Oral Invest. 2017;5(21):1675-80.

33. Bell R, Arcury TA, Anderson AM, Chen H, Savoca MR, Gilbert GH, et al. Dental anxiety and oral health outcomes among rural older adults. J Public Health Dent. 2012;72(1):53-9.

34. Eitner S, Wichmann M, Paulsen A, Holst S. Dental anxiety-an epidemiological study on its clinical correlation and effects on oral health. J Oral Rehabil. 2006;33(8):588-93.

35. Merskey H, Bogduk N. Clsssification of Chronic Pain: Descriptions of Chronic Pain Synfroms and Definition of Pain Terms. Seattle: IASP Press; 1994.

36. Maggirias J, Locker D. Psychological factors and perceptions of pain associated with dental treatment. Community Dent Oral Epidemiol. 2002;30(2):151-9.

37. Muhney KA, Dechow PC. Patients' perception of pain during ultrasonic debridement: a comparison between piezeoelectric and magnetostrictive scalers. J Dent Hygiene. 2010(84): 185-9.

38. Pandit N, Gupta R, Chandoke U, Gugnani S. Comparative evaluation of topical and electronic anesthesia during scaling and root planing. J Periodontal. 2010;81(7):1035-40.

39. Tickle M, Milsom K, Crawford FIJ, Aggarwal VR. Predictors of pain associated with routine procedures performed in general dental practice. Community Dent Oral Epidemiol. 2012;40(4):34350 .

40. Fardal O, McCulloch CA. Impact of anxiety on pain perception associated with periodontal and implant surgery in a private practice. J Periodontol. 2012;83(9):1079-85.

41. Staunton G. Applied behavioural analysis principles in dentistry: techniques to overcome dental fear, improving attendance and compliance. J Ir Dent Assoc. 2018;1(64):30-4.

42. Armfield JM, Stewart JF, Spencer AJ. The vicious cycle of dental fear: exploring the interplay between oral health, service utilization and dental fear. BMC Oral Health. 2007;7:1.

43. Tonetti MS, Greenwell H, Kornman KS. Staging and grading of periodontitis: Framework and proposal of a new classification and case definition. J Clin Periodontol. 2018;45 Suppl 20:149 - 61. 
44. Meusel DDRZ, Ramacciato JC, Motta RHL, Júnior RBB, Flório FM. Impact of the severity of chronic periodontal disease on quality of life. J Oral Sci. 2015;57(2):87-94.

\section{Figures}

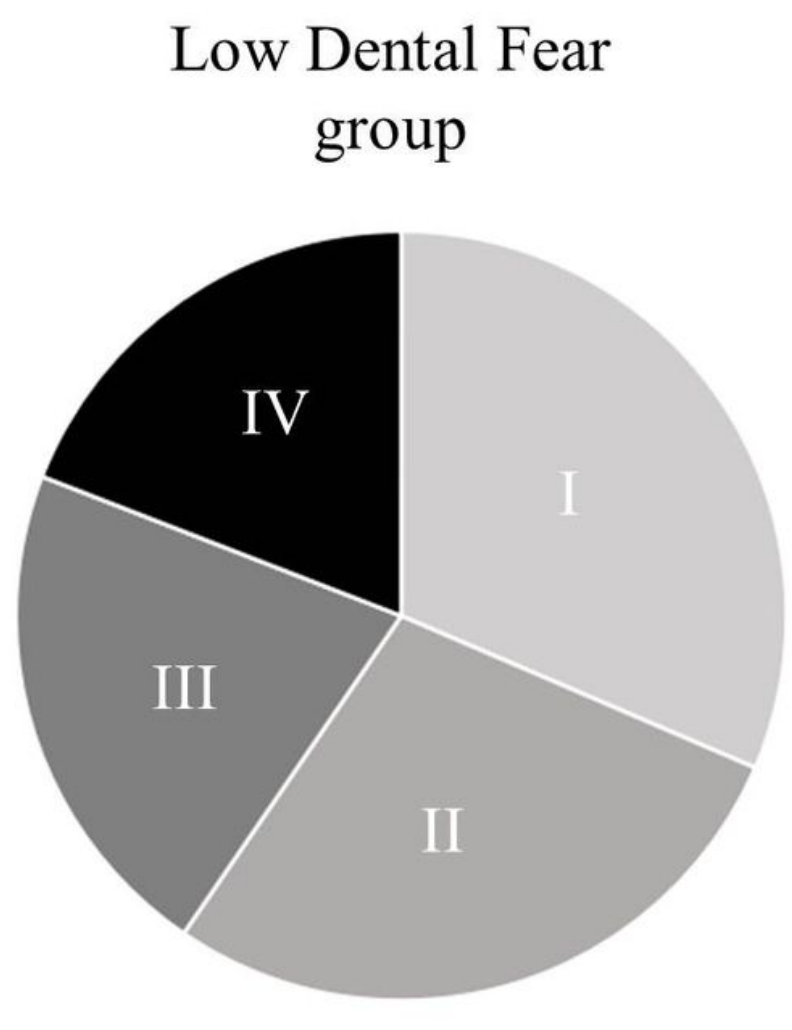

$\mathrm{DAS}<13$

\section{High Dental Fear group}

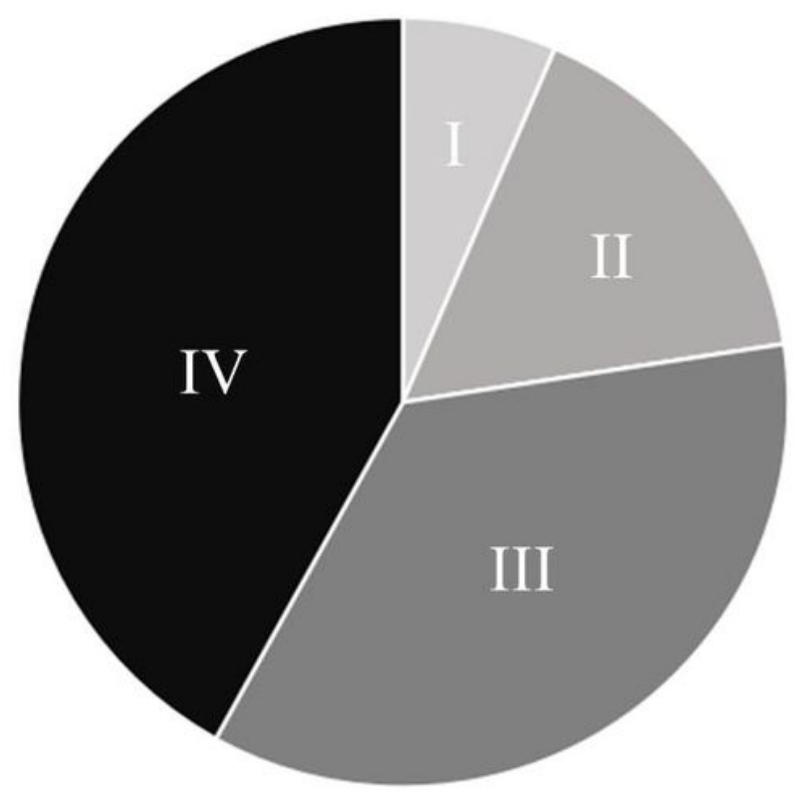

$\mathrm{DAS} \geq 13$

\section{Figure 1}

Distribution according to DAS. Differences between two DAS levels were significant $(P=0.003)$. 